\title{
Stent Encrustation due to Forgotten Double-J Stents: A Series of Five Cases
}

\author{
Unutulmuş Double-J Stentlere Bağlı Stent Enkrustasyonunun Görüldüğü Beş Serilik Olgu \\ Sunumu
}

\author{
(1) Salih Bürlukkara, (1) Aykut Aykaç, (1) Özer Baran \\ Karabük University Faculty of Medicine, Department of Urology, Karabük, Turkiye
}

\begin{abstract}
Although Double-J stents have become very common in the urological practice and are effectively used for various reasons, several complications related to it, such as hematuria, infection, irritative symptoms, pain, perforation, encrustation, and migration, have been observed. The present study reports five case reports of stent encrustation due to forgotten stents.

Keywords: Double-J, Kidney stone, Urolithiasis, Percutaneous nephrolithotomy, Lithotripsy

öz

Üroloji pratiğinde, Double-J stentler çeşitli nedenlerle etkili bir şekilde kullanılır. Hematüri, enfeksiyon, irritatif semptomlar, ağrı, perforasyon, taşlaşma, migrasyon gibi komplikasyonlar görülebilir.Unutulmuş Double-J stentlere bağlı gelişen stent enkrustasyonu ile ilgili beş olgu sunumu sunuyoruz.
\end{abstract}

Anahtar Kelimeler: Double-J, Böbrek Taşı, Ürolitiazis, Perkütan nefrolitotomi, Taşlaşma

\section{Introduction}

While Double-J (DJ) stent has become an essential tool in the modern urological practice, there has been a significant increase in the number of complications and side effects such as urinary tract infection, hematuria, irritative voiding symptoms, and encrustation related to ureteral stents with the increasing use of it in urology clinics. One of the most prominent of these complications is stent encrustations due to forgotten ureteral stents. Urinary obstruction due to stent encrustations can typically lead to problems such as hydronephrosis, loss of renal function, and urosepsis $(1,2)$. Numerous methods including some minimally invasive procedures such as ureterorenoscopic lithotripsy, percutaneous nephrolithotomy, and open surgical methods have been used in the literature for the treatment of stent encrustations due to forgotten DJ stents $(3,4)$. This study presents five cases with stent encrustation due to forgotten DJ stents and the removal of these stents with holmium laser and percutaneous intervention.

\section{Case Presentation}

\section{Case 1}

A 28-year-old male patient with dysuria was admitted to our clinic in November 2019. The anamnesis of the patient revealed that he was operated in 2014 due to an external left ureteric stone. A DJ stent was implanted, and the patient did not come to postoperative controls. A kidney, ureter, and bladder (KUB) radiograph showed a DJ stent with encrustation at both ends, one end extending from the kidney to the iliac cross level and the other end in the bladder (Figure 1). The patient underwent one session of cystolithotripsy and one session of percutaneous nephrolithotomy one month later.

\section{Case 2}

A 49-year-old male patient with hematuria was admitted to our clinic in May 2019. The anamnesis revealed that the patient was operated in 2016 due to right kidney stone in an external center

Correspondence: Salih Bürlukkara MD, Karabük University Faculty of Medicine, Department of Urology, Karabük, Turkiye E-mail: dr.salihb.kara@gmail.com ORCID-ID: orcid.org/0000-0002-2149-0163

Received: 11.01.2020 Accepted: 19.05.2020

Cite this article as: Bürlukkara S, Aykaç A, Baran Ö. Stent Encrustation due to Forgotten Double-J Stents: A Series of Five Cases. J Urol. Surg 2020;7(3):245-

247.

${ }^{\circledR}$ Copyright 2020 by the Association of Urological Surgery / Journal of Urological Surgery published by Galenos Publishing House. 
and did not come to the controls. A KUB radiograph showed an encrusted DJ stent fragment extending from the kidney to proximal ureter with its distal part in the bladder. Of note, the cystolithotripsy and ureterorenoscopy were both performed in the same session.

\section{Case 3}

A 53-year-old male patient with no active complaints was referred to our clinic after a visit to another outpatient clinic due to mental retardation in February 2018, during which a forgotten right DJ stent was found in the patient. The anamnesis of the patient revealed that he had undergone ureterolithotomy due to proximal ureteral stone in 2016 and did not come to controls. An abdominopelvic CT showed a DJ stent extending from the kidney to the bladder with an encrusted proximal end. The proximal part was cleared of encrustations by ureterorenoscopic holmium laser lithotripsy.

\section{Case 4}

A 47-year-old male patient was admitted to our clinic with the complaint of a foreign body coming out from urethra during urination in September 2019. The medical history of the patient revealed an operation performed in an external center due to left ureteral stone in 2012. A KUB radiograph revealed a spontaneous severed DJ stent extending from the left kidney to the distal part of the ureter with its distal part in the bladder (Figure 2). A two-stage operation was planned, and the patient underwent one session of cystolithotripsy followed by a session of left percutaneous nephrolithotomy one month later.

\section{Case 5}

A 54-year-old male patient with hematuria was admitted to our clinic in August 2017. The anamnesis of the patient revealed

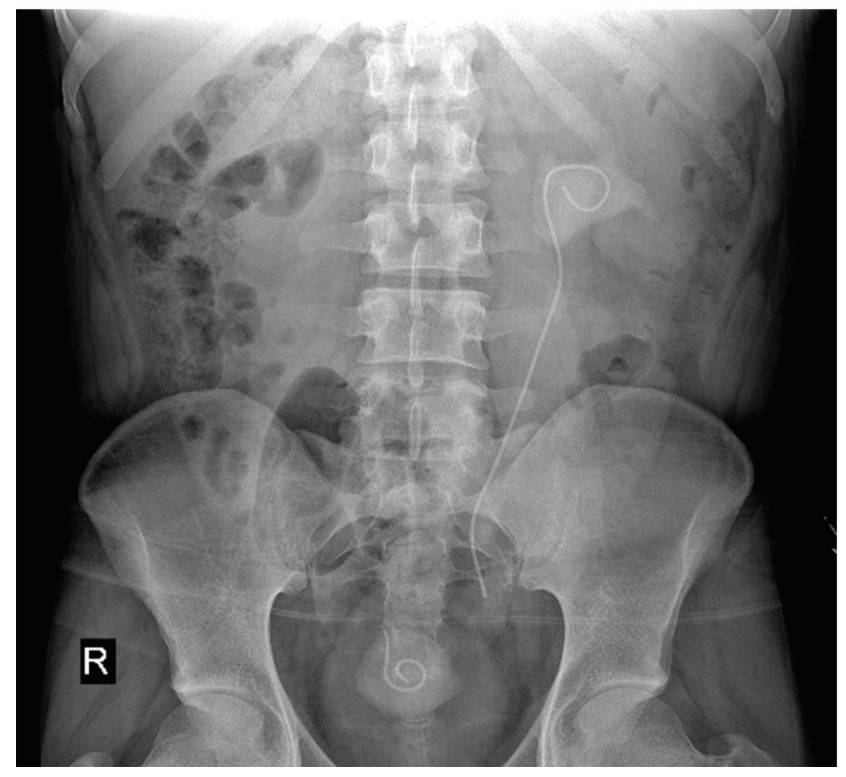

Figure 1. Kidney, ureter, and bladder radiograph that he was operated due to right kidney stone in 2013 and did not come to the controls. A KUB radiograph showed a spontaneous ruptured DJ stent with proximal part in the right kidney and distal part in the bladder. The patient underwent one session of cystolithotripsy and one session of right percutaneous nephrolithotomy one month later. Informed consent was obtained from all the patients before the operations.

\section{Discussion}

DJ stents are widely used in urology to provide urine flow between the kidney and bladder in various operations such as renal stone surgery, retroperitoneal fibrosis, genitourinary system injuries, renal transplantation, and reconstructive surgical procedures $(5,6)$.

Stents are generally made using polyurethane, polyethylene, and silicone materials. While stents made of silicone can be kept in the body for longer periods, stents made of polyurethane or polyethylene should be replaced every eight weeks (7). Moreover, DJ stenting has late complications such as hydronephrosis, stent migration, encrustation, and fragmentation $(8,9)$, and one of the most important in terms of its results is stent encrustation that may develop due to ureteral stents forgotten in the body for long periods of time. In addition, life-threatening complications such as loss of renal function and urosepsis may also develop as a result of urinary obstruction due to stent encrustations (2). Encrustations developing in DJ stents after being forgotten or long-term applications may cause problems during stent removal. Treatment modalities such as percutaneous nephrolithotomy, ureterorenoscopic pneumatic lithotripsy, and laser lithotripsy can be used for this purpose (9).

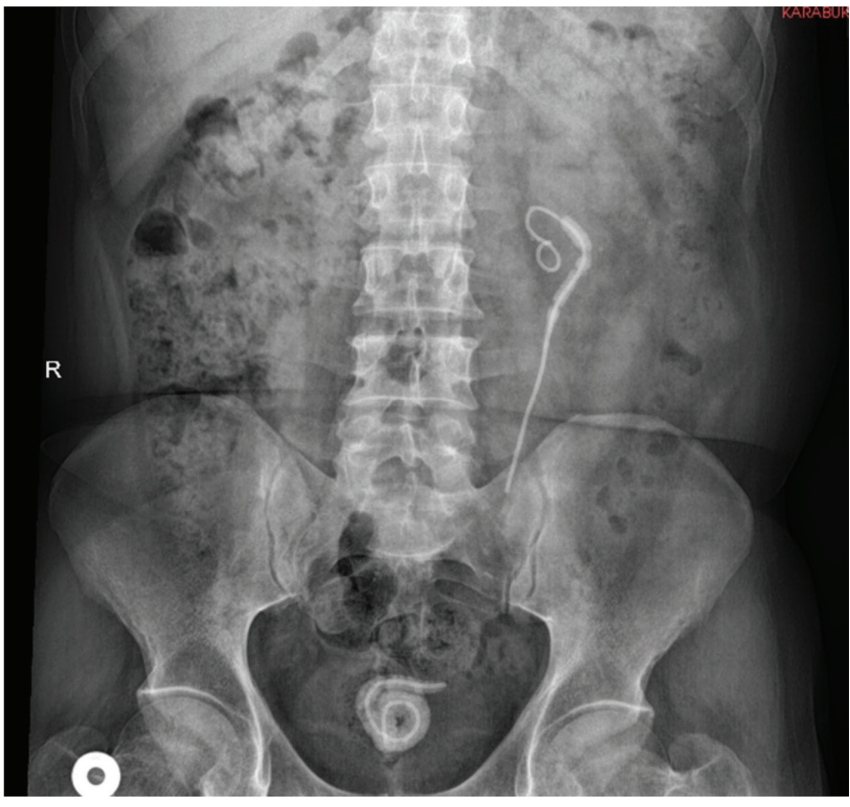

Figure 2. Kidney, ureter, and bladder radiograph 
To conclude, we suggest that while selecting the appropriate treatment modality, the encrustation load around the stent, its location, and surgical equipment should be considered and possible options should be discussed with the patient. Patients treated with ureteral stents should be informed in detail about the stent, and the ureteral stent should be removed as soon as possible.

\section{Ethics}

Informed Consent: Informed consent was obtained from all the patients before the operations.

Peer-review: Externally and internally peer-reviewed.

\section{Authorship Contributions}

Concept: S.B., Design: S.B., Data Collection or Processing: S.B. Analysis or Interpretation: A.A., Literature Search: Ö.B., Writing: S.B.

Conflict of Interest: No conflict of interest was declared by the authors.

Financial Disclosure: The authors declared that this study received no financial support.

\section{References}

1. Saltzman B. Ureteral stents. Indications, variations, and complications. Urol Clin North Am 1988;15:481-491.

2. Soylu A, Altunoluk $B$, Günes $A$, Baydinç $Y C$. Kidney loss due to forgotten ureteral stent. Türk Üroloji Dergisi 2004;30:245-248.

3. Singh I, Gupta NP, Hemal AK, Aron M, Seth A, Dogra PN. Severely encrusted polyurethane ureteral stents: management and analysis of potential risk factors. Urology 2001;58:526-531.

4. Canby-Hagino ED, Caballero RD, Harmon WJ. Intraluminal pneumatic lithotripsy for the removal of encrusted urinary catheters. J Urol 1999;162:2058-2060

5. Kibar Y, Akay O, Erdemir F, Dayanç M. Unutulmuş üreteral çift J stentin piyelolitotomi ile çıkarılması. Gülhane Tıp Dergisi 2005;47:218-220.

6. H. Seymour, Uday Patel. Ureteric Stenting-Current Status. Semin intervent Radiol 2000;17:351-366.

7. Damiano R, Oliva A, Esposito C, De Sio M, Autorino R, D'Armiento M, Damiano R, Oliva A, Esposito C, De Sio M, Autorino R, D'Armiento M. Early and late complications of double pigtail ureteral stent. Urol Int 2002;69:136-140.

8. Pollard SG, Macfarlane R. Symptoms arising from Double-J ureteral stents. J Urol 1998;139:37-38.

9. Somers WJ. Management of forgotten or retained indwelling ureteral stents. Urology 1998;47:431-435. 